\title{
RENDIMENTOS AGRÍCOLA E FORRAGEIRO DE TRÊS CULTIVARES DE CANA- DE-AÇÚCAR (Saccharum spp.) EM DIFERENTES ÉPOCAS DE CORTE
}

\author{
Agricultural and forage yields of three sugarcane (Saccharum spp.) cultivars \\ at different cutting times
}

\begin{abstract}
Humberto Simplício de Castro ${ }^{1}$, Luiz Antônio de Bastos Andrade ${ }^{2}$, Elberis Pereira Botrel ${ }^{3}$, Antônio Ricardo Evangelista ${ }^{4}$
\section{RESUMO}

Objetivou-se, neste trabalho, avaliar os rendimentos agrícola e forrageiro de três cultivares de cana-de-açúcar em diferentes épocas de corte (maio, julho e setembro), onde há uma maior demanda de forragem na região. O experimento foi instalado no município de Lavras, Minas Gerais. O clima é do tipo mesotérmico e o solo é um Latossolo Vermelho Escuro. O delineamento experimental utilizado foi o de blocos casualizados, em esquema fatorial 3 X 3, com 3 repetições. Os tratamentos foram constituídos por três cultivares de cana-de-açúcar (RB825336; SP80-1816 e RB835054) e por três épocas de corte (maio; julho; setembro). Cada parcela foi constituída por 6 linhas de cana-de-açúcar, espaçadas de $1,25 \mathrm{~m}$, com $8 \mathrm{~m}$ de comprimento, com uma área total de $60 \mathrm{~m}^{2}$. A área útil de parcela correspondeu às quatro linhas centrais, eliminando-se $1,0 \mathrm{~m}$ de cada extremidade, com uma área de $30,0 \mathrm{~m}^{2}$. Foram avaliados os rendimentos de massa verde, massa seca, tonelada de colmos por hectare e sacarose (g/100g caldo). Os resultados mostraram que não houve efeitos de cultivares e das épocas de corte estudadas nos rendimentos dos colmos, massa verde, matéria seca e sacarose da cana-de-açúcar. Os altos rendimentos obtidos para massa verde e matéria seca, no período de seca (maio a setembro), mostram o grande potencial da cana-de-açúcar para uso na alimentação do rebanho leiteiro na região.
\end{abstract}

Termos para indexação: Cana para forragem, massa verde e matéria seca.

\begin{abstract}
Our main goal in this study was to evaluate the agricultural and forage yields of three sugarcane cultivars at different cutting times (May, July and September), when there is a larger demand for forage in the region. The experiment was installed in the municipal district of Lavras, Minas Gerais. The climate is of the mesothermic type, and the soil is a Dark Red Latossolo. The experimental delineation used was of casualized blocks in 3 X 3 factorial design, with 3 repetitions. The treatments consisted of three cultivars of sugarcane (RB825336; SP80-1816; and RB835054) and three cutting times (May; July; September). Each plot consisted of 6 sugarcane rows, spaced at $1,25 \mathrm{~m}$, with $8 \mathrm{~m}$ of length, and with a total area of $60 \mathrm{~m}^{2}$. The useful area corresponded to the four central rows, $1,0 \mathrm{~m}$ of each extremity being eliminated, with an area of $30,0 \mathrm{~m}^{2}$. Green mass, dry mass, stems per hectare, and sucrose $(\mathrm{g} / 100 \mathrm{~g}$ broth) were appraised. The results showed that the cultivars and the cutting times studied had no effect on the yields of the stems, green mass, dry mass, and sugarcane sucrose (broth). The high yields obtained for green mass and dry matter, during the drought period (May to September), show the great potential of sugarcane for use in dairy cattle feeding in the area.
\end{abstract}

Index terms: Sugarcane forage, green mass and dry mass.

(Recebido em 27 de março de 2008 e aprovado em 28 de outubro de 2008)

\section{INTRODUÇÃO}

A cana-de-açúcar é uma gramínea semiperene, pertencente ao gênero Saccharum, própria de climas tropicais e subtropicais, possivelmente originária do sudeste da Oceania. O início da cultura no Brasil coincide com os primórdios da colonização portuguesa.

Constitui-se, atualmente, como uma das culturas de grande importância socioeconômica para o Brasil; seus principais derivados são o açúcar (alimento) e o álcool (hidratado e anidro), imprescindíveis ao mercado. Outros produtos, também originados dessa cultura e que devem ser salientados, são a aguardente (muito consumida), a massa verde e a matéria seca usadas na alimentação animal, o bagaço, que é utilizado principalmente como fonte de energia mas pode ser usado na alimentação animal (PEREIRA et al, 2008) e a vinhaça, que serve de fertilizante na própria cultura.

\footnotetext{
'Engenheiro Agrônomo, Mestre em Agronomia/Fitotecnia - Consultor Autônomo - R: Prof. W. Novaes, 56, Apto 101 - 37200-000 - Lavras,MG humbertosimplício@yahoo.com.br

Engenheiro Agrônomo,Doutor em Agronomia/Produção Vegetal - Departamento de Agricultura/DAG - Universidade Federal de Lavras/UFLA - Cx. P. 3037 - 37200-000 - Lavras,MG - laba@ufla.br

${ }^{3}$ Engenheiro Agrônomo, Doutor em Agronomia/Fitotecnia - Departamento de Agricultura/DAG - Universidade Federal de Lavras/UFLA - Cx. P. 3037 37200-000 - Lavras,MG - elberis@ufla.br

${ }^{4}$ Engenheiro Agrônomo, Doutor em Zootecnia - Departamento de Zootecnia/DZO - Universidade Federal de Lavras/UFLA - Cx. P. 3037 - $37200-000$ Lavras,MG - aricardo@ufla.br
} 
A cana-de-açúcar sofre as influencias das condições climáticas ao longo do ano (ANJOS et al, 2007), sendo que a planta precisa encontrar condições de temperatura e umidade adequadas que permitam um desenvolvimento suficiente durante a fase vegetativa, seguida de um período com restrição hídrica e/ou térmica para forçar o repouso vegetativo o enriquecimento em sacarose na época do corte (Alfonsi et al., 1987).

Beauclair (2004) menciona que a programação de corte de uma lavoura de cana-de-açúcar é uma atividade fundamental na rentabilidade do empreendimento, pois pode aumentá-la praticamente sem custo adicional. Ressalta porém, que existem poucos trabalhos que tratam do assunto, com o objetivo de auxiliar a tomada de decisões sobre o cronograma de corte. Além disso, como o melhoramento genético é muito dinâmico e novas cultivares são lançadas a cada ano, há sempre necessidade de estudos envolvendo a interação cultivar $\mathrm{X}$ época de corte para uma condição edafo-climática especifica.

As cultivares de cana-de-açúcar destinadas à produção de açúcar e álcool são normalmente utilizadas para a produção de forragem, já que normalmente não existem trabalhos de melhoramento genético para esse fim.

Do total de cana-de-açúcar produzida no Brasil, estimase que cerca de $10 \%$ destina-se a alimentação animal. Seria algo em torno de 30 milhões de toneladas de forragem verde, suficientes para suplementar 15 milhões de bovinos durante 150 dias ao ano. Hoje, a cana-de-açúcar tem se tornado um volumoso de uso preferencial entre os pecuaristas por apresentar características tais como possibilidade de sua conservação mediante silagem, persistência da cultura e o grande rendimento obtido em nossas condições (Embrapa, 1997).

Como a região de Lavras - MG caracteriza-se como uma bacia leiteira, onde a cana-de-açúcar é muito utilizada na alimentação do gado (Silva et al., 2007), objetivou-se neste trabalho avaliar os rendimentos agrícola e forrageiro de três cultivares de cana-de-açúcar em diferentes épocas de cortes (maio, julho e setembro), quando ocorre uma maior demanda de cana para forragem.

\section{MATERIALE MÉTODOS}

O experimento foi instalado em área da Aguardente Bocaina, no município de Lavras, Minas Gerais, localizado a $21^{\circ} 14^{\prime} 30^{\prime \prime}$ latitude $\mathrm{S}$ e $45^{\circ} 00^{\prime} 10^{\prime \prime}$ Longitude W.

O clima, de acordo com a classificação de Köppen, é do tipo Cwb: clima mesotérmico, de verões brandos e chuvosos. As temperaturas do mês mais frio e do mais quente são de $18^{\circ}$ e $22^{\circ}$, respectivamente, com temperatura media anual de $19,3^{\circ}$ C. Constata-se que os índices pluviométricos anuais situam-se em torno de $1400 \mathrm{~mm}$, sendo o período mais chuvoso de Dezembro a Março (65\% do total pluviométrico anual) e o período de estiagem coincide com os meses de inverno( junho a Agosto, com 3,5\% do total pluviométrico anual).

O solo onde foi instalado o experimento, caracterizase como Latossolo Vermelho Escuro, de topografia plana, cujos resultados das analises químico e granulométricas estão apresentados na Tabela 1.

Tabela 1 - Características químico e granulométricas do solo utilizado no ensaio, profundidades de 0-20 e 20-40cm. UFLA, Lavras-MG. 2005.

\begin{tabular}{lcc}
\hline & Profundidade $(\mathrm{cm})$ & \\
\hline \multicolumn{1}{c}{ Determinações } & $0-20$ & $20-40$ \\
\hline Ph em água & $5,5 \mathrm{AcM}$ & $2 \mathrm{AcM}$ \\
$\mathrm{P}(\mathrm{ppm})$ & $3 \mathrm{~B}$ & $23 \mathrm{~B}$ \\
$\mathrm{~K}(\mathrm{ppm})$ & $67 \mathrm{M}$ & $0,8 \mathrm{~B}$ \\
$\mathrm{Ca}(\mathrm{meq} / 100 \mathrm{cc})$ & $1,7 \mathrm{M}$ & $0,4 \mathrm{~B}$ \\
$\mathrm{Mg}(\mathrm{meq} / 100 \mathrm{cc})$ & $0,9 \mathrm{M}$ & $0,1 \mathrm{~B}$ \\
$\mathrm{Al}(\mathrm{meq} / 100 \mathrm{cc})$ & $0,1 \mathrm{~B}$ & $3,2 \mathrm{M}$ \\
$\mathrm{H}+\mathrm{A}(\mathrm{meq} / 100 \mathrm{cc})$ & $3,6 \mathrm{M}$ & $1,3 \mathrm{~B}$ \\
$\mathrm{~S}($ meq/100cc) & $2,8 \mathrm{M}$ & $4,5 \mathrm{~B}$ \\
$\mathrm{~T}($ meq/100cc) & $6,4 \mathrm{M}$ & $28 \mathrm{~B}$ \\
V (\%) & $43 \mathrm{~B}$ & $1,7 \mathrm{M}$ \\
Carbono (\%) & $2,2 \mathrm{~A}$ & $2,9 \mathrm{M}$ \\
Matéria Orgânica $(\%)$ & $3,8 \mathrm{~A}$ & 8 \\
Areia (\%) & 9 & 22 \\
Limo (\%) & 29 & 70 \\
Argila $(\%)$ & 62 & \\
\hline
\end{tabular}

Analises realizada nos Laboratórios de Fertilidade e Física do Solo do Departamento de Ciências do Solo da Universidade Federal de Lavras-MG. 
O delineamento experimental utilizado foi o de blocos casualizados, em esquema fatorial $3 \times 3$, com 3 repetições. Os tratamentos foram constituídos por três cultivares de cana-de-açúcar (RB825336; SP80-1816 e RB835054) e por três épocas de corte (Maio; Julho; Setembro de 2006).

A cultivar RB825336 é considerada de alta produtividade agrícola, alto teor de sacarose, maturação precoce, alto número de colmos por metro, baixa exigência em fertilidade do solo, difícil florescimento e tolerante às principais doenças (UFSCAR, 1992).

A cultivar RB835054 é considerada de alta produtividade agrícola, alto teor de sacarose, maturação precoce, alto número de colmos por metro, baixa exigência em fertilidade do solo, não floresce e tolerante às principais doenças (Silveira et al., 2002).

A cultivar SP80-1816 é considerada de alta produtividade agrícola, alto teor de sacarose, maturação média, médio número de colmos por metros, média exigência em fertilidade do solo, não floresce e tolerante às principais doenças (Silveira et al., 2002).

Cada parcela foi constituída por 6 linhas de canade-açúcar, espaçadas de $1,25 \mathrm{~m}$, com $8 \mathrm{~m}$ de comprimento, com uma área total de $60 \mathrm{~m}^{2}$. A área útil de parcela correspondeu às quatro linhas centrais, eliminando-se $1,0 \mathrm{~m}$ de cada extremidade, com uma área de $30,0 \mathrm{~m}^{2}$.

Após o preparo do solo, que constou de uma aração e duas gradagens realizou-se o plantio da cana-de-açúcar em fevereiro de 2005, aplicando-se no sulco o equivalente a $500 \mathrm{Kg} \cdot \mathrm{ha}^{-1}$ da fórmula 08-28-16. Aos 60 dias após o plantio, aplicou-se $60 \mathrm{Kg}_{\mathrm{g}} \mathrm{ha}^{-1}$ de $\mathrm{N}$, por se tratar de área de colheita de cana crua (CFSEMG, 1999).

O controle de plantas daninhas, sempre que necessário, foi realizado de forma manual, mantendo-se a cultura livre de competição, principalmente nos primeiros 100 dias pós-plantio, período esse, considerado critico para matocompetição na cultura da cana-de-açúcar - cana de ano-e-meio (Andrade \& Andrade, 2007).

A colheita foi realizada de forma manual, sem queima prévia do canavial, para avaliar rendimentos de colmos, massa verde, matéria seca e sacarose.

O rendimento de massa verde (colmos + ponteiros + folhas laterais) foi obtido por meio de pesagens realizadas em balança tipo dinamômetro, com capacidade para 120 $\mathrm{kg}$, de acordo com metodologia preconizada por Mariotti \& Lascano (1969), citados por Arizono et al. (1998). Posteriormente, realizou-se a transformação para toneladas por hectare.

Após pesagem da massa verde total, os colmos despontados e despalhados foram novamente pesados em balança tipo dinamômetro, calculando-se o peso de colmos na área útil da parcela e, posteriormente, em toneladas de colmo por hectare (TCH).

E para rendimento de massa seca por hectare, cinco canas integrais (colmos + ponteiros + folhas laterais), colhidas aleatoriamente de cada parcela, foram passadas em picadeira convencional para forragem e após homogeneização do material, foram retiradas quantidades próximas de $500 \mathrm{~g}$, colocadas em estufa a $65^{\circ} \mathrm{C}$, até obterse peso constante. Calculou-se assim, a porcentagem de matéria seca que foi então multiplicada pela produção de massa verde total, obtendo-se a produção de massa seca por hectare.

O parâmetro sacarose ( $\mathrm{g} / 100 \mathrm{~g}$ caldo) foi obtido no Laboratório de Ciência dos Alimentos da UFLA, por meio de análise preconizada pela Coopersucar (1980).

Os dados foram analisados empregando-se o Software Sisvar (Ferreira, 2000).

\section{RESULTADOS E DISCUSSÃO}

Nenhuma das variáveis estudadas, cultivares de cana-de-açúcar e épocas de corte, assim como sua interação, foi significativa para as características rendimentos de massa verde e matéria seca $\left(\mathrm{t} . \mathrm{ha}^{-1}\right)$, toneladas de colmo por hectare $\left(\mathrm{t}^{\mathrm{h}} \mathrm{h}^{-1}\right)$ e sacarose $(\mathrm{g} / 100 \mathrm{~g}$ caldo) (Tabela 2).

Os valores médios obtidos para rendimentos de massa verde e matéria seca, em função das épocas de colheita e cultivares, são apresentados na Tabela 3.

Os altos valores obtidos para rendimentos de massa verde e matéria seca, principalmente no período de intensa seca, julho a setembro, evidenciaram o grande potencial da cana-de-açúcar para uso na alimentação do rebanho leiteiro na região, estando de acordo com Faria (1993), Landell et al. (2002) e Silva et al. (2007). Estes valores de MS estão em concordância com a maioria dos trabalhos apresentados na literatura (Carvalho, 1992; Aroeira et al., 1993; Pereira et al., 1996; Miranda et al., 1999; Rodrigues \& Barbosa, 1999; Pereira et al., 2001).

Os valores médios obtidos para rendimentos de colmos são apresentados na Tabela 4. Deve ser ressaltado que as três cultivares são consideradas de alto rendimento agrícola (UFSCar, 1992; Silveira et al., 2002).

Os valores obtidos para toneladas de colmo por hectare $(\mathrm{TCH})$ foram superiores àqueles relatados por Garcia (2005), que também trabalhou com cana de primeiro corte, nessa mesma região.

Os valores médios obtidos para sacarose $(\mathrm{g} / 100 \mathrm{~g}$ caldo), em função das cultivares e das épocas de colheita, são observados na Tabela 4. 
Tabela 2 - Resumo do quadro de análise de variância dos dados obtidos para massa verde, matéria seca, rendimento de colmos e sacarose. UFLA, 2007.

\begin{tabular}{|c|c|c|c|c|c|}
\hline \multirow{2}{*}{ Causa de variação } & \multirow[b]{2}{*}{ GL } & \multicolumn{4}{|c|}{ QM } \\
\hline & & $\begin{array}{c}\text { Massa verde } \\
\left(\text { t.ha }^{-1}\right)\end{array}$ & $\begin{array}{c}\text { Matéria seca } \\
\left(\text { t.ha }^{-1}\right)\end{array}$ & $\begin{array}{l}\text { Toneladas de colmo } \\
\text { por hectare }\left(\mathrm{t} \mathrm{ha}^{-1}\right)\end{array}$ & $\begin{array}{l}\text { Sacarose } \\
(\mathrm{g} / 100 \mathrm{~g})\end{array}$ \\
\hline Cultivares (C) & 2 & 25191,12 & 7933,98 & 29545,18 & 7,68 \\
\hline Épocas (E) & 2 & 6654,70 & 4315,89 & 2566,08 & 193,91 \\
\hline $\mathrm{CxE}$ & 4 & 15666,87 & 1193,98 & 7332,28 & 50,04 \\
\hline Blocos & 2 & 15615,05 & 2174,82 & 12606,17 & 60,42 \\
\hline Erro & 16 & 21639,42 & 5090,32 & 13810,41 & 118,77 \\
\hline Total & 26 & --- & --- & --- & --- \\
\hline $\mathrm{CV}(\%)$ & & 10,15 & 16,35 & 9,47 & 5,75 \\
\hline
\end{tabular}

* significância a nivel de $5 \%$ de probabilidade.

Tabela 3 - Valores médios de rendimentos de massa verde (MV) (t.ha $\left.{ }^{-1}\right)$ e matéria seca (MS) (t.ha $\left.{ }^{-1}\right)$, para as diferentes cultivares e épocas de corte. UFLA, Lavras, MG, 2007.

\begin{tabular}{|c|c|c|c|c|c|c|c|c|}
\hline \multirow[b]{3}{*}{ Cultivares } & \multicolumn{6}{|c|}{ Épocas de corte } & \multirow{3}{*}{$\begin{array}{c}\text { Médias } \\
\text { (MV) }\end{array}$} & \multirow{3}{*}{$\begin{array}{c}\text { Médias } \\
\text { (MS) }\end{array}$} \\
\hline & \multicolumn{2}{|c|}{ Maio } & \multicolumn{2}{|c|}{ Julho } & \multicolumn{2}{|c|}{ Setembro } & & \\
\hline & MV & MS & MV & MS & MV & MS & & \\
\hline RB825336 & 144,89 & 41,01 & 139,40 & 46,62 & 149,87 & 48,78 & 144,72 & 45,47 \\
\hline RB835054 & 144,71 & 38,79 & 138,30 & 38,87 & 136,49 & 42,93 & 139,83 & 40,20 \\
\hline SP80-1816 & 160,08 & 44,54 & 148,78 & 44,95 & 142,35 & 46,10 & 150,40 & 45,20 \\
\hline Médias & 148,07 & 41,59 & 143,99 & 43,35 & 142,90 & 45,94 & & \\
\hline
\end{tabular}

Tabela 4 - Valores médios de toneladas de colmo por hectare $(\mathrm{TCH})\left(\mathrm{t} \cdot \mathrm{ha}^{-1}\right)$ e sacarose $(\mathrm{g} / 100 \mathrm{~g}$ caldo), para as diferentes cultivares e épocas de corte. UFLA, Lavras, MG, 2007.

\begin{tabular}{|c|c|c|c|c|c|c|c|c|}
\hline \multirow[b]{3}{*}{ Cultivares } & \multicolumn{6}{|c|}{ Épocas de corte } & \multirow[b]{3}{*}{$\begin{array}{l}\text { Médias } \\
\text { (TCH) }\end{array}$} & \multirow[b]{3}{*}{$\begin{array}{c}\text { Médias } \\
\text { (Sacarose) }\end{array}$} \\
\hline & \multicolumn{2}{|c|}{ Maio } & \multicolumn{2}{|c|}{ Julho } & \multicolumn{2}{|c|}{ Setembro } & & \\
\hline & $\mathrm{TCH}$ & $\begin{array}{l}\text { Saca } \\
\text { rose }\end{array}$ & $\mathrm{TCH}$ & $\begin{array}{l}\text { Saca } \\
\text { rose }\end{array}$ & $\mathrm{TCH}$ & $\begin{array}{l}\text { Saca } \\
\text { rose }\end{array}$ & & \\
\hline RB825336 & 117,44 & 18,87 & 119,50 & 19,31 & 127,73 & 18,56 & 121,55 & 18,92 \\
\hline RB835054 & 124,33 & 18,68 & 116,72 & 19,20 & 118,84 & 18,76 & 119,96 & 18,88 \\
\hline SP80-1816 & 134,29 & 19,48 & 130,18 & 19,63 & 127,29 & 18,05 & 130,59 & 19,06 \\
\hline Médias & 125,35 & 19,01 & 122,13 & 19,38 & 124,62 & 18,46 & & \\
\hline
\end{tabular}

A cana-de-açúcar destaca-se como uma planta com elevado potencial para transformar energia solar em energia química, representada principalmente pela sacarose. $\mathrm{O}$ elevado teor deste nutriente na planta madura, justamente numa época do ano em que as pastagens são escassas e deficientes em proteína e energia, faz da cana uma importante fonte energética para bovinos durante o período seco (Embrapa, 1997).

Segundo o IAPAR (2008), o valor nutritivo aumenta com a idade da planta, recomendando assim o uso de cana madura. Deve ser ressaltado que, com base na sacarose (\%) caldo, a cana é considerada madura quando apresenta 
teor igual ou maior que 14,4\% (Andrade, 2006). Assim, com base nessa característica, pode-se inferir que as três cultivares encontravam-se maduras nas três épocas de colheitas estudadas (maio, julho e setembro).

\section{CONCLUSÕES}

Não houve efeitos de cultivares e das épocas de corte estudadas nos rendimentos dos colmos, massa verde, matéria seca e sacarose da cana-de-açúcar. Os altos rendimentos obtidos para massa verde e matéria seca, no período de seca (maio a setembro), mostram o grande potencial da cana-de-açúcar para uso na alimentação do rebanho leiteiro na região.

\section{REFERÊNCIAS BIBLIOGRÁFICAS}

ALFONSI, R.R.; PEDRO JUNIOR, M.J.; BRUNINI, O.; BARBIERI, V. Condições climaticas para cana-de-açúcar. In: PARANHOS, S.B. (Coord.). Cana-de-açúcar: cultivo e utilização. Campinas: Fundação Cargill, 1987. v.1, p.42-55.

ANDRADE, L.A. de B. Cultura da cana-de-açúcar. In: CARDOSO, M. das G. Produção de aguardente de cana. Lavras: UFLA, 2006. p.26-67.

ANDRADE, L.A. de B.; ANDRADE, P.P. Implantação e condução de canaviais. Informe Agropecuário, Belo Horizonte, v.28, n.239, p.44-54, jul./ago. 2007.

ANJOS, I. A. dos; ANDRADE, L. A. de B.; GARCIA, J. C.; FIGUEIREDO, P. A. M. de; CARVALHO, G. J. de. Efeitos da adubação orgânica e da época de colheita na qualidade da matéria-prima e nos rendimentos agrícola e de açúcar mascavo artesanal de duas cultivares de canade-açúcar (cana-planta).Ciência e Agrotecnologia, Lavras, v.31, n.1, p.59-63, jan./fev., 2007.

ARIZONO, H.; MATSUOKA, S.; GHELLER, Y.; MASUDA, H.P.; HOFFMANN, B.A.I.; MENESEZ, L.L. Alternativas para avaliação de produção de cana-deaçúcar. STAB, Açúcar, Álcool e Subprodutos, Piracicaba, v.16, n.5, p.20, maio/jun. 1998.

AROEIRA, L.J.M.; SILVEIRA, M.I.; LIZIEIRE, R.S. Degrababilidade no rúmen e taxa de passagem da canade-açúcar mais uréia, do farelo de algodão e do farelo de arroz em novilhos mestiços europeu x zebu. Revista Brasileira de Zootecnia, Viçosa, v.22, n.4, p.52-564, 1993.

BEAUCLAIR, E.G.F. de. Planejamento e estimativa na produção de cana. Visão Agrícola, Piracicaba, v.1, n.1, jan./jun. 2004.
CARVALHO, G.J. Avaliação do potencial forrageiro e industrial de variedades de cana-de-açúcar (ciclo de ano) em diferentes épocas de corte. 1992. 63f.

Dissertação (Mestrado em Fitotecnia)-Universidade Federal de Lavras, Lavras, 1992.

COMISSÃO DE FERTILIDADE DO SOLO DO ESTADO DE MINAS GERAIS. Recomendações para o uso de corretivos e fertilizantes em Minas Gerais: $5^{\text {a }}$ aproximação. Viçosa, MG: UFV, 1999. 359p.

\section{COOPERATIVA CENTRAL DOS PRODUTORES DE} AÇÚCAR E ÁLCOOL DO ESTADO DE SÃO PAULO. Amostragem e análise da cana-de-açúcar. São Paulo, 1980. 37p.

EMPRESA BRASILEIRA DE PESQUISA AGROPECUÁRIA. Utilização da cana-de-açúcar na alimentação de bovinos: gado de corte divulga, Campo Grande, MS. Disponível em: <http:// IWww.cnpgc.embrapa.br/publicacoes/divulga/ GCD23.html>. Acesso em: 12 ago. 2007.

FARIA, V.P. O uso da cana-de-açúcar para bovinos no Brasil. In:SIMPÓSIO SOBRE NUTRIÇÃO DE BOVINOS, 5., 1993, Piracicaba, SP. Anais... Piracicaba: Ferla, 1993. p.1-16.

FERREIRA, D.F. Análises estatísticas por meio do SISVAR para Windows versão 4.0. In: REUNIAOANUAL DA REGIAO BRASILEIRA DA SOCIEDADE INTERNACIONAL DE BIOMETRIA, 45., 2000, São Carlos, SP. Anais... São Carlos: UFSCAR, 2000. v.1, p.225, 258p.

GARCIA, J.C. Efeitos da adubação orgânica, associada ou não à adubação química, calagem e fosfatagem, nos rendimentos agrícola e de aguardente teórica da canade-açúcar (Saccharum spp). Lavras: UFLA, 2005. 82p.

IAPAR. Cana-de-açúcar: excelente alternativa para alimentar bovinos no inverno. Disponível em: <http:// 'www.iapar.br/arguivos/File/zip_pdf/ncana.pdf خ. Acesso em: 23 set. 2008 .

LANDELL, M.G.A.; CAMPANA, M.P.; RODRIGUES, A.A.; CRUZ, G.M.; BATISTA, L.A.R.; FIGUEIREDO, P.; SILVA, M.A.; BIDOIA, M.A.P.; ROSSETO, R.; MARTINS, A.L.; GALLO, P.B.; KANTHACK, R.A.D.; CAVICHIOLI, J.C.; VASCONCELOS, A.C.M.; XAVIER, M.A.A variedade IAC86-2480 como nova opção de cana-de-açúcar para fins forrageiros: manejo de produção e uso na alimentação. Campinas: Instituto Agronômico, 2002.36p. (Boletim técnico IAC, 193). 
MIRANDA, L.F.; QUEIROZ, A.C.; VALADARES FILHO, S.C. Desempenho e desenvolvimento ponderal de novilhas leiteiras alimentadas com dietas à base de canade-açúcar. Revista Brasileira de Zootecnia, Viçosa, v.28, n.3, p.605-613, 1999.

PEREIRA, R. A. N.; FERREIRA, W. M.; GARCIA, S. K.; PEREIRA, M. N.; BERTECHINI, A. G. Digestibilidade do bagaço de cana-de-açúcar tratado com hidróxido de sódio em dietas para coelhos em crescimento. Ciência e Agrotecnologia, Lavras, v.32, n.2, p.573-577, mar./abr., 2008.

PEREIRA, E.S.; QUEIROZ, A.C.; PAULINO, M.F. Fontes nitrogenadas e uso de Sacharomyces cereviseae em dietas à base de cana-de-açúcar para novilhos: consumo, digestibilidade, balanço nitrogenado e parâmetros ruminais. Revista Brasileira de Zootecnia, Viçosa, v.30, n.2, p.563-572, 2001.

PEREIRA, O.G.; GARCIA, R.; VALADARES FILHO, S.C. Consumo e digestibilidade total e parcial dos nutrientes de dietas contendo cana-de-açúcar (Saccharum officinarum L.), sob diferentes formas, em bovinos. Revista Brassileira de Zootecnia, Viçosa, v.25, n.4, p.750-762, 1996.

RODRIGUES, A.A.; BARBOSA, P.F. Efeito do teor protéico do concentrado no consumo da cana-de-açúcar com uréia e ganho de peso de novilhas em crescimento.

Revista Brasileira de Zootecnia, Viçosa, v.28, n.2, p.421424, 1999.

SILVA, E.A. da; FERREIRA, J.J.; RUAS, J.R.M.; PAES, J.M.V.; MACEDO, G.A.R. Utilização da cana-de-açúcar na alimentação de ruminantes. Informe Agropecuário, Belo Horizonte, v.28, n.239, p.102-119, jul./ago. 2007.

SILVEIRA, L.C.I. da; BARBOSA, M.H.P.; OLIVEIRA, M.W. de. Manejo de variedades de cana-de-açúcar predominantes nas principais regiões produtoras de cachaça de Minas Gerais. Informe Agropecuário, Belo Horizonte, v.23, n.217, p.25-32, 2002.

UNIVERSIDADE FEDERAL DE SÃO CARLOS. Centro de Ciências Agrárias. Cinco novas variedades RB de cana-deaçúcar para São Paulo. Araras: UFSCAR, 1992. 19p. 